\title{
Beyond the Representation: Cognition in Manipulative Learning Objects within Learning Simple Equations
}

\author{
Hsiu-Ju Chang
}

\begin{abstract}
The representations of learning objects are the essential objects for individual reasoning and cognizing during teaching and learning processes on web-based educational system. The different representations of the concepts will maintain different knowledge structures and algorithms to show specific directions for information recognition and acquisition. This paper will focus on the relationships between different types of concept representations and individuals' learning styles. We argue whether the learning styles may help learning performances within three types of concept representations. And we pay attention to the representation types of learning objects will alleviate cognitive load or embedded cognition adaptively to enhance learning performance. Participants were 88 junior high school students (grade 7, 12 15 years old, 44 males, 44 females) with different achievement and ambition of individual learners.
\end{abstract}

Index Terms-Learning style, cognitive load, adaptive learning.

\section{INTRODUCTION}

In visualization, learning objects will base on some structures and contexts for individuals to realize and generate specific meanings. Whatever the static, dynamic, or manipulative representations usually maintain different explanation, guidance, and hint for individual to interpret and realize the visualizations. In general, different representations will maintain different structures, directions, inferences, and interactions for individual to realize and cognize information. Furthermore, the different characteristics of material representations will embed specific situated cognition environments for individual to make assimilation and accommodation. In adaptation, a suitable design for situated cognition may involve the specific domain knowledge and adaptable inference which are based on individual schemas and experiences. However, the cognitive processes of knowable contents can be occurred automatically which allow individual to bypass individual's working memory. Simultaneously, the acceptances for individual to learn the knowable contents may limit to individual's schemas and experiences. Consequently, individual may fail or refuse to know the related materials. Meanwhile, the construct and deconstruct to design learning objects and knowledge representations are the essential factors to effect individual's cognition processes. In situated cognition, learning is the interactions of individual and environment situations. Furthermore, each learning and

Manuscript received May 16, 2014; revised July 22, 2014.

Hsiu-Ju Chang is with National Chengchi University, Taiwan (e-mail: changhsiuju@gmail.com). teaching processes usually involve the interactions among prior knowledge, learning experience, teaching treatment, material representation, and construct and deconstruct of design objects. We tried to design three types of knowledge representations which were manipulative, iconic, and symbolic representations under the equivalent concepts.

\section{Common Vulnerabilities of Web-BASed TEAChing / LEARNING MATERIALS}

\section{A. Vulnerabilities of Web-Based Educational System}

Vulnerabilities are unsuitable constructions and access control in teaching/learning environment. Common reasons for vulnerabilities of web-based educational system include the following: 1) To neglect the cognitive levels between teaching/learning materials and learners' characteristics. 2) To express the same representations or presentations on single teaching material that will neglect multiple presentations of adaptive factors and multi-cognitive channels for learners to learn. 3) Teacher may have difficulties to diagnosis possible misconceptions of learners in multi-cognitive concepts in a teaching material. 4) In generally, the adaptively educational system may arrange materials form easy to difficult but what are principles to distribute the teaching materials into different difficult levels. 5) There are many multimedia teaching materials to be displayed in various ways on web pages but the diverse multimedia teaching materials lack some mechanisms to direct the multimedia teaching materials to teaching or learning processes adaptively. 6) As we know the progress of web technologies improve rapidly, but what are the channels to perform the technologies take effect or enhance the effect on educational system.

\section{B. Inabilities of Representation of Learning Objects}

And, the inabilities of representation of learning objects are 1) lack of retention for individual to recall information; 2) lack to focus on prior knowledge or experience to be the bases for individual learners to build their mental pictures or schemas; 3) lack of suitable structures [1] or designs for concept comprehensions [1]-[3].

\section{LEARNING STYLE}

The index of learning styles questionnaire (ILS) [4], is an instrument to identify which tendencies of learning styles belong to learners and which representations of teaching objects are suitable for learners. The ILS results provide an indication of an individual's learning preferences and an even better indication of the preference profile of learners. The 
differences will effect on personal learning process. The ILS used to assess preferences on four dimensions (active/reflective, sensing/intuitive, visual/verbal, and sequential/global) of learning styles. The ILS inventory consists of 44 paired items to detect four dimension learning style profile provides an indication of possible strengths and possible tendencies or habits of learners. In this experiment, we changed the dichotomous questions to 5 point Likert scale ranging from "Strongly Disagree like my tendency", "Somewhat Disagree like my tendency", "Somewhat agree like my tendency", "Strongly agree like my tendency", and "I am not sure". The reliabilities and validities are reported in the Table I. The cronbach's alpha of sensing style is 0.933 , visual style is 0.905 , and verbal style is 0.921 . The AVE (Average Variance Extracted), composite reliability, and cronbachs's alpha values are showed in Table I.

TABLE I: THE AVE, COMPOSITE RELIABILITY, AND CRONBACHS'S ALPHA

\begin{tabular}{|c|c|c|c|}
\multicolumn{4}{|c|}{ VALUE OF THREE CONSTRUCTS } \\
constructs & AVE & $\begin{array}{c}\text { Composite } \\
\text { Reliability }\end{array}$ & $\begin{array}{c}\text { Cronbachs's } \\
\text { Alpha }\end{array}$ \\
\hline Sensing & 0.600 & 0.943 & 0.933 \\
\hline Verbal & 0.514 & 0.921 & 0.905 \\
\hline Visual & 0.560 & 0.933 & 0.921 \\
\hline
\end{tabular}

TABLE II: The Cross LoAding TABLE OF SENSING, VerbaL, AND Visual

\begin{tabular}{|c|c|c|c|}
\hline \multicolumn{4}{|c|}{ NING STYLES } \\
\hline & Sensing & Verbal & Visual \\
\hline Sensing1 & 0.824 & 0.531 & 0.616 \\
\hline Sensing2 & 0.781 & 0.495 & 0.592 \\
\hline Sensing3 & 0.778 & 0.432 & 0.582 \\
\hline Sensing4 & 0.792 & 0.469 & 0.605 \\
\hline Sensing5 & 0.764 & 0.476 & 0.613 \\
\hline Sensing6 & 0.778 & 0.550 & 0.570 \\
\hline Sensing7 & 0.733 & 0.567 & 0.576 \\
\hline Sensing8 & 0.754 & 0.515 & 0.525 \\
\hline Sensing9 & 0.799 & 0.494 & 0.641 \\
\hline Sensing10 & 0.792 & 0.556 & 0.644 \\
\hline Sensing11 & 0.717 & 0.518 & 0.488 \\
\hline Verbal1 & 0.486 & 0.710 & 0.423 \\
\hline Verbal2 & 0.475 & 0.719 & 0.394 \\
\hline Verbal3 & 0.492 & 0.727 & 0.464 \\
\hline Verbal4 & 0.460 & 0.740 & 0.392 \\
\hline Verbal5 & 0.414 & 0.711 & 0.368 \\
\hline Verbal6 & 0.538 & 0.780 & 0.414 \\
\hline Verbal7 & 0.449 & 0.705 & 0.441 \\
\hline Verbal8 & 0.522 & 0.757 & 0.398 \\
\hline Verbal9 & 0.494 & 0.698 & 0.463 \\
\hline Verbal10 & 0.467 & 0.670 & 0.331 \\
\hline Verbal11 & 0.400 & 0.657 & 0.372 \\
\hline Visual1 & 0.617 & 0.447 & 0.775 \\
\hline Visual2 & 0.588 & 0.431 & 0.756 \\
\hline Visual3 & 0.521 & 0.369 & 0.728 \\
\hline Visual4 & 0.583 & 0.468 & 0.750 \\
\hline Visual5 & 0.532 & 0.428 & 0.737 \\
\hline Visual6 & 0.551 & 0.452 & 0.745 \\
\hline Visual7 & 0.527 & 0.373 & 0.769 \\
\hline Visual8 & 0.563 & 0.416 & 0.786 \\
\hline Visual9 & 0.555 & 0.402 & 0.753 \\
\hline Visual10 & 0.569 & 0.389 & 0.704 \\
\hline Visual11 & 0.616 & 0.465 & 0.726 \\
\hline
\end{tabular}

In addition, the construct validities are illustrated on Table II. Convergent and discriminant validity both are subtypes of construct validity. And the convergent validities and cross factor loadings of three constructs are showed in Table II. We can see the convergent and discriminant validity of variables. The more loading factors that variables have, the more convergent validity will be happened. And the discriminant validity means that correlations among the variables are low. We find a good result of convergent and discriminant validity in Table II and Table III.

TABLE III: THE LATENT VARIABLE CORRELATIONS AMONG SENSING, VERBAL, AND VISUAL LEARNING STYLES

\begin{tabular}{|l|l|l|l|}
\hline & Sensing & Verbal & Visual \\
\hline Sensing & $\mathbf{0 . 7 7 4 3 8 9 4}$ & & \\
\hline Verbal & 0.662497 & $\mathbf{0 . 7 1 6 6 6 3 1}$ & \\
\hline Visual & 0.758174 & 0.567484 & $\mathbf{0 . 7 4 8 4 8 9 1}$ \\
\hline
\end{tabular}

The discriminate validity of sensing construct is 0.774 . The discriminate validity of verbal construct is 0.716 . The discriminate validity of visual construct is 0.748 .

\section{PResentation TyPeS AND LEARNing Styles of DIGITAL CONTENT}

The experiments integrated the ILS [4] and cognitive representations [5]. The mechanisms direct the multimedia or digital content as materials to enhance adaptive teaching/learning processes, the mechanisms are the follows: 1) Sensing tendency $\rightarrow$ Enactive representation $\rightarrow$ Manipulative materials; 2) Visual tendency $\rightarrow$ Iconic representation $\rightarrow$ Visual aid materials; 3) Verbal tendency $\rightarrow$ Symbolic representation $\rightarrow$ Text materials; 4) Sequential tendency $\rightarrow$ Sequential learning $\rightarrow$ Not to jump learning levels; 5) Global tendency $\rightarrow$ May non-sequential learning $\rightarrow$ If possible then jump learning levels; For the multi-feature of phenomena express each teaching concepts in more than one expression that will benefit on learners' knowledge comprehension, multi-cognitive channels, and plenty descriptions of teaching concept [3], [6]. The relationships of knowledge representations and phenomenon are showed in the follows: 1) If individual's learning style is sensing tendency then the knowledge representation will be manipulative aid representation. 2) If individual's learning style is iconic tendency then the knowledge representation will be visual aid representation. 3) If individual's learning style is symbolic tendency then the concept or knowledge representation will be descriptions/symbols/text aid representation.

\section{IDENTIFICATION AND SEGMENTATION}

Owning to working memory is limited by both individual's capacity [7], [8] and duration [9]. Accordingly, none stops or none segmentations of transitory information [10] will create more extraneous cognitive loads by increasing the demands on individual's working memory to process the old and new information[11], [12]. The intended purposes of cognitive load are to support the suitable learning materials in well designs which maintain the suitable representations [13] and cognitive channels for individual characteristics. In cognitive 
load theory, the cognitive processes and individuals' learning experiences will influence and conduct individual's learning performance. Bannert (2002) [14] asserted two issues of cognitive load: 1) how to manage the cognitive loads during teaching and learning processes; 2) the external and internal cognitive loads are the components of the management. Furthermore, intrinsic cognitive load is based on the learner's cognitive architecture and determined by the amount of element interactions. Owing to the automatic cognition schemas of thinking, learning, and solving processes are always based on learners' comprehensible and meaningful connections among concepts, skills, and applications. Meanwhile, the utilizations of automatic cognition schemas need dynamically and adaptively to access the specific knowledge, comprehension, and application in time.

\section{PROCEDURE}

Owing to the different representations will build the different mental images, logical analogy meanings, and surface meanings by learners themselves. Therefore, we are not easy to realize which representation meanings could be interpreted and translated by individual learners. Consequently, the misunderstandings, misconceptions, and the faults of the main concepts or problems are not easy to detect and solve. Furthermore, learners will comprehend via the web pages to build their knowledge. Meanwhile, the more individual access to digital materials, the more knowledge representations need to be focus. Accordingly, concept expressions and knowledge representations will be the essential mechanisms for the instruction design to guide and assist learners to create evident understandings, build mental images and verify individual comprehension during learning and solving processes.

TABLE IV: THE CHANGEABLE AND UNCHANGEABLE OF THE EQUIVALENT

\begin{tabular}{|c|c|c|}
\hline & Unchangeable & Changeable \\
\hline Essential concept & 0 & \\
\hline Expression & & 0 \\
\hline Objective & 0 & \\
\hline Reasoning & & 0 \\
\hline Activities & & 0 \\
\hline Cognitive level & 0 & \\
\hline Difficult level & 0 & \\
\hline Representation type & & \\
\hline
\end{tabular}

However, the different expressions will maintain the distinct designs in knowledge visualization, recognition, and organization. Hence, the different thinking, reasoning, perceiving, and conjecturing processes will affect the teaching and learning performances. Correspondingly, the distinct concept representations will lead individual learners to think, reason, and conjecture differently. In this experiment, we identified the equivalent learning object which maintains some criteria are equivalent for designer to develop the knowledge representations. The changeable and unchangeable properties of the equivalent learning objects are illustrate in Table IV. After setting of the properties, the representations will follow the properties to develop the manipulative, iconic, and symbolic learning objects for individual to learn. The unchangeable properties of the knowledge for development are essential concept, objective, cognitive level, and difficult level. And the unchangeable properties are expression, reasoning, activities, and representation type.

TABLE V: THE TENDENCY DEGREES OF THREE LEARNING STYLE
\begin{tabular}{|l|c|}
$\begin{array}{l}\text { The tendency degrees of } \\
\text { three learning style }\end{array}$ & Number \\
\hline Sensing (Se) & 8 \\
\hline Verbal $(\mathrm{Ve})$ & 43 \\
\hline Visual $(\mathrm{Vi})$ & 16 \\
\hline $\mathrm{Se}=\mathrm{Ve}$ & 4 \\
\hline $\mathrm{Se}=\mathrm{Vi}$ & 0 \\
\hline $\mathrm{Ve}=\mathrm{Vi}$ & 3 \\
\hline $\mathrm{Se}=\mathrm{Ve}=\mathrm{Vi}$ & 1 \\
\hline $\mathrm{Bad}$ sample & 2 \\
\hline
\end{tabular}

\section{RESULT AND CONCLUSION}

Participants were 88 junior high school students (grade 7 , 12 15 years old, 44 males, 44 females) with different achievement and ambition of individual learners. The difference intervals between verbal and visual tendency are the follows: 1) Sixty-two individuals are belong to $0 \sim 10$ interval; 2) Eleven individuals are belong to 11 20 interval; 3) Four individuals are belong to 21 30 interval; The difference intervals between verbal and sensing tendency are the follows: 1) Sixty-seven individuals are belong to $0 \sim 10$ interval; 2) Eight individuals are belong to 11 20 interval; 3) Two individuals are belong to $21 \sim 30$ interval; The difference intervals between sensing and visual tendency are the follows: 1) Sixty-two individuals are belong to $0 \sim 10$ interval; 2) Eleven individuals are belong to 11 20 interval; 3) Four individuals are belong to 21 30 interval.

After we analyzed the differences among the sensing, verbal, and visual learning styles, we counted scores to find the greatest tendency of all individuals. The Table V showed the distributions of individual's learning styles. In Table V, the data shows that the most of individual's learning styles is verbal tendency. And the second is visual tendency. There are seven learners who have the same tendencies. In addition, two samples filled the same choices in the questionnaire. We may infer that learners will have better performances on verbal representation, symbolic representation. However, every individual has all learning styles which has different degree tendency of leaning styles. Consequently, we developed manipulative, iconic, and symbolic representations for all individuals to learn and test. After the learning and testing processes, we compared the learning performances among manipulative, iconic, and symbolic representations which were mapping to sensing, visual, and verbal learning styles.

Furthermore, we analyzed the learning performances 
which were based on manipulative, iconic, and symbolic representations under the equivalent learning objects. All of participants learned all digital learning materials. And the performances are illustrated on Table VI. The percentage of 100 points is $86.6 \%$ of symbolic representation. The percentage of 100 points is $91 \%$ of iconic representation. In manipulative representation, the percentage of 100 points is $31.1 \%$. We find the best learning performance is iconic representation. And the second is symbolic representation. The manipulative representation is the last one in all representations. Nonetheless, the manipulative representations almost need more efforts and time for designers to construct and develop the essential concepts.

TABLE VI: THE LEARNING PERForMANCES OF THREE TYPES OF MATERIAL

\begin{tabular}{|c|c|c|c|c|c|c|}
\hline \multicolumn{7}{|c|}{ REPRESENTATION } \\
\hline$\times$ & MR & MR $(\%)$ & SR & SR $(\%)$ & IR & IR $(\%)$ \\
\hline 100 & 38 & $31.1 \%$ & 78 & $86.7 \%$ & 82 & $91.1 \%$ \\
\hline 80 & 10 & $8.2 \%$ & 7 & $7.8 \%$ & 4 & $4.4 \%$ \\
\hline 60 & 6 & $4.9 \%$ & 2 & $2.2 \%$ & 1 & $1.1 \%$ \\
\hline 40 & 12 & $9.8 \%$ & 0 & $0.0 \%$ & 0 & $0.0 \%$ \\
\hline 20 & 12 & $9.8 \%$ & 0 & $0.0 \%$ & 0 & $0.0 \%$ \\
\hline 0 & 10 & $8.2 \%$ & 1 & $1.1 \%$ & 1 & $1.1 \%$ \\
\hline Total Number & 88 & & & & & \\
\hline
\end{tabular}

MR: Manipulative Representation

SR: Symbolic Representation

IR: Iconic Representation

Participants were 88 junior high school students who were grate 7 . These students have not learned this topic. The example of symbolic representation of the simple equation is like $x+9=15$. And the example of iconic representation is illustrates in Fig. 1. Finally, the Fig. 2 is showed the manipulative representation.

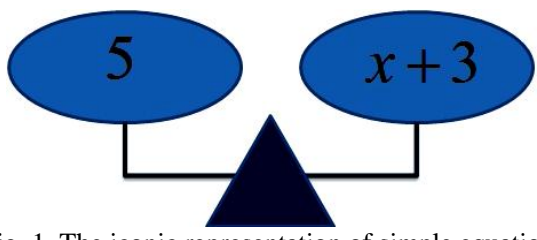

Fig. 1. The iconic representation of simple equation.

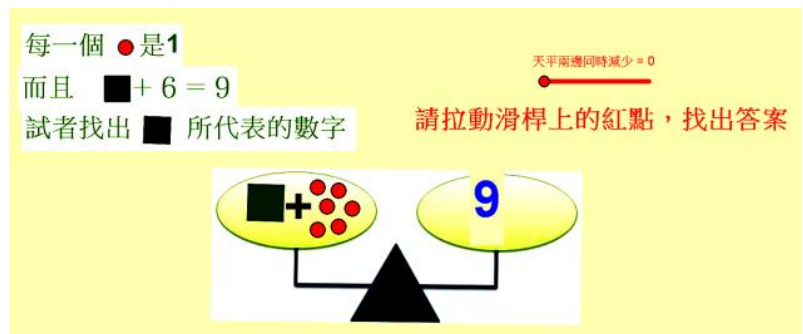

Fig. 2. The manipulative representation of simple equation.

Hypothesis 1: Will the learning outcome effect by the learning style?

Hypothesis 2: Will the individual learning styles have different effect on specific material representation?

Hypothesis 3: Do the manipulative representation support sensing tendency learners to enhance the learning performance?
Hypothesis 4: Do the symbolic representation support verbal learners to enhance the learning performance?

Hypothesis 5: Do the visual representation support iconic tendency learners to enhance the learning performance?

Table VII illustrates the learning performances of three types of learning styles and three kinds of knowledge representations have relationships between individuals and materials. The learning performances were significant different while learners with distinct learning style tendencies study the suitable learning materials.

TABLE VII: THE LEARNING PERFORMANCES WERE SIGNIFICANT DIFFERENT WHILE LEARNERS WITH DISTINCT LEARNING STYLE TENDENCIES STUDY THE SUITABLE LEARNING MATERIALS

\begin{tabular}{|c|c|c|c|}
\hline \multirow[b]{2}{*}{ Learning style } & \multicolumn{3}{|c|}{ Performance } \\
\hline & Sensing & Visual & Verbal \\
\hline Sensing Style & $0.000 *$ & 0.276 & 0.13 \\
\hline Visual Style & 0.147 & $0.00 *$ & 0.903 \\
\hline Verbal Style & 0.76 & 0.97 & $0.000 *$ \\
\hline$R^{2}$ & 0.873 & 0.884 & 0.889 \\
\hline
\end{tabular}

The structural features of learning materials are aspects for deconstruction or reconstruction for giving the concepts or operations specific meanings and applications. However, novice learners can not be experts to know and distinguish meanings and applications in different structural features [1], [15]-[17]. Consequently, the concept framework and representation structure are the essential criteria for learners to comprehend and understand learning materials. In this research, we select equivalent objectives, simple equations, which involve the symbolic, iconic, and manipulative learning objects for individual's comprehensions and applications. To sum up, we found that learning styles (sensing, visual, and verbal) and the different representations (manipulative, iconic, and symbolic) maintained some relationships during individuals' learning processes.

\section{REFERENCES}

[1] G. Corbalana, L. Kestera, and J. J. G. V. MerriënboerJeroen, "Dynamic task selection: Effects of feedback and learner control on efficiency and motivation," Learning and Instruction, vol. 19, pp. 455-465. 2009.

[2] H. J. Chang, "Adaptation in depth: The use of "cognitive object-oriented teaching mode'," in Proc. World Conference on Educational Multimedia, Hypermedia and Telecommunications, E. Pearson and P. Bohman, eds., Chesapeake, VA: AACE. Press, USA, 2006, pp. 751-758.

[3] H. J. Chang, "Information management of cognitive object-oriented teaching model," in Proc. The 11th Asian Technology Conference in Mathematics, Advanced Technology Council in Mathematics, The Hong Kong Polytechnic University, Hong Kong SAR, China, 2006, pp. 250-259.

[4] R. M. Felder and B. A. Soloman. (July 2014). Index of Learning Styles Questionnaire. [Online]. Available: http://www.engr.ncsu.edu/learningstyles/ilsweb.html

[5] J. S. Bruner, Toward a Theory of Instruction, Cambridge, Mass.: Harvard University Press, 1966.

[6] H. J. Chang, "Adaptation-in-depth educational system within the rule base reasoning," in Proc. World Conference on Educational Multimedia, Hypermedia and Telecommunications, E. Pearson \& P. Bohman, eds., Chesapeake, VA: AACE. Press, USA, 2007, pp. 1110-1115.

[7] N. Cowan, "The magical number 4 in short-term memory: A reconsideration of mental storage capacity," Behavioral and Brain Sciences, vol. 24, pp. 87-185, Feb. 2001. 
[8] J. Sweller, J. V. Merrienboer, and F. Paas, "Cognitive architecture and instructional design," Educational Psychology Review, vol. 10, pp 251-296, Sept. 1998.

[9] G. A. Miller, "The magical number seven, plus or minus two: Some limits on our capacity for processing information," Psychological Review, vol. 63, pp. 81-97, March 1956.

[10] A. Wong, W. Leahy, N. Marcus, and J. Sweller, "Cognitive load theory, the transient information effect and e-learning," Learning and Instruction, vol. 22, pp. 449-457.

[11] P. Ayres and F. Paas, "Can the cognitive load approach make instructional animations more effective," Applied Cognitive Psychology, vol. 21, pp. 811-822, Sept. 2007.

[12] P. Ayres and F. Paas, "A cognitive load approach to the learning effectiveness of instructional animation," Applied Cognitive Psychology, vol. 21, Sept. 2007.

[13] J. L. Quilici and R. E. Mayer, "Teaching students to recognize structural similarities between statistics word problems," Applied Cognitive Psychology, vol. 16, pp. 325-342, March 2002.

[14] M. Bannert, "Managing cognitive load - Recent trends in cognitive load theory," Learning and Instruction, vol. 12, pp. 139-146, Feb. 2002.
[15] D. D. Cummins, "The role of analogical reasoning in the induction of problem categories," Journal of Experimental Psychology: Learning, Memory, and Cognition, vol. 18, pp. 1103-1124. Sept. 1992.

[16] L. R. Peterson and M. J. Peterson, "Shortterm retention of individual verbal items," Journal of Experimental Psychology, vol. 58, pp. 193-198, Sept. 1959

[17] J. L. Quilici and R. E. Mayer, "Role of examples in how students learn to categorize statistics word problems," Journal of Educational Psychology, vol. 88, pp. 144-161, Mar. 1996.

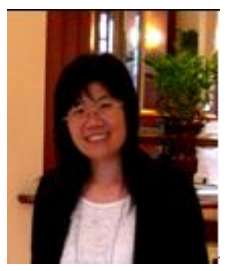

Hsiu-Ju Chang received the M.S. degree in degree program of e-learning from National Chiao Tung University, Hsinchu, Taiwan, R.O.C., in 2003. And she is now a third year Ph.D. student in the Department of Education at National Chengchi University in Taipei, Taiwan, R.O.C. Her research interests include adaptive learning, cognitive constructing, and active thinking in traditional and digital teaching, learning environment. 